\title{
Using the TACT Framework to Learn the Principles of Rigour in Qualitative Research
}

\author{
Ben K. Daniel \\ University of Otago, Dunedin, New Zealand \\ ben.daniel@otago.ac.nz \\ DOI: $10.34190 / J B R M .17 .3 .002$
}

\begin{abstract}
Assessing the quality of qualitative research to ensure rigour in the findings is critical, especially if findings are to contribute to theory and be utilised in practice. However, teaching students concepts of rigour and how to apply them to their research is challenging. This article presents a generic framework of rigour with four critical dimensionsTrustworthiness, Auditability, Credibility and Transferability (TACT) intended to teach issues of rigour to postgraduate students and those new to qualitative research methodology. The framework enables them to explore the key dimensions necessary for assessing the rigour of qualitative research studies and checklist questions against each of the dimensions. TACT was offered through 10 workshops, attended by 64 participants. Participants positively evaluated the workshops and reported that the workshops enable them to learn the principles of qualitative research and better understanding issues of rigour. Work presented in the article is part of a large research programme investigating the pedagogy of research methods in higher education.
\end{abstract}

Keywords: Rigour, trustworthiness, auditability, credibility, transferability, methods pedagogy, TACT

\section{Introduction}

The growing diversity in the application of various methods in qualitative research necessitates a critical look at the way we assess the quality of research to ensure that the findings are rigorous and useful. There is a growing consensus in the literature regarding the importance of ensuring rigour in qualitative studies (Guba and Lincoln, 1981; Lietz et al., 2006; Morse et al., 2002; Morse, 2015; Noble \& Smith, 2015). Tong and Dew (2016) suggested that qualitative studies must be conducted using a rigorous approach and that the findings need to be comprehensively reported. It has been shown that achieving rigour in the qualitative study requires that findings can be applied to solve problems (e.g. patient care) (Noble \& Smith, 2015). Issues of rigour and relevance are likely to increase in complexity depending on the types of research questions, actors involved in the project, scope and size of the project (Camfield, 2019). As complexity increases, so is the need to achieve and maintain consistency in the approach, analysis and reporting of the research outcomes.

Though it is widely known that issues of rigour are essential to teach in qualitative research methods, the literature remains polarised regarding how rigour can be achieved in qualitative research. Some researchers have advocated for the development of universal sets of criteria and standards for judging qualitative research based on interpretative ontologies (Shenton, 2004; Koch et al. 2014). Others suggested that the outcome of a qualitative research study needs to undergo the same quality assurance process, similar to the one used in quantitative research (Morse et al., 2002). However, the adoption of general guidelines for evaluating qualitative research studies has been criticised because such standards would likely ignore the complexity of the individual qualitative research project (Yardley, 2000; Dixon-Woods et al., 2004), and grossly violate the epistemic interpretative nature of the qualitative methodology.

In other words, unlike quantitative research where measures are aimed at establishing objectivity, replicability, validity and reliability, qualitative research methodology is an epistemic enterprise, whereby the researcher interprets the meaning of data based on what is observed, how it was observed, enriched by personal reflections and experiences of the social world, relative to what is being studied (Cypress, 2017; El Hussein, Jakubec, \& Osuji, 2015; Hartman, 2015; Noble \& Smith, 2015).

Despite the polarised views on how to achieve rigour, the provision of a generic framework is necessary for teaching research methods to students (Daniel, 2018). Also, a general framework can serve as a decisionsupport for new qualitative researchers, since conducting meaningful qualitative research involves making many decisions, some of which might appear complex for the new researcher, as such providing a set of criteria is essential. This article presents a theoretical framework developed to help postgraduate students and those new to qualitative research use a set of indicators to guide them in assessing rigour in qualitative 
research. The framework composes of the following indicators or dimensions: trust, auditability, credibility, and transferability (TACT). From the four dimensions, a list of questions is provided to the users of the framework to help them think about various issues that can contribute to a rigorous and useful outcome of research findings. Further, a number of workshops were offered to test the framework. The workshops were then evaluated to find the experiences of participants.

\section{The TACT framework}

The dimensions presented in the TACT framework (see Figure 1) were identified from the literature. The framework developed as a guide for students to think about issues of rigour in qualitative research studies and provide a general understanding of strategies that can be used to achieve rigour. TACT can also be used as a guide for those interested in inspecting the quality of research outcomes (e.g. peer-review of qualitative research methods or examination of doctoral theses). Also, teachers of qualitative research methods can use TACT as a teaching tool. The intent of developing TACT is congruent with Koch (2006) guidelines for evaluating the quality, and Morse et al. (2002) proposal for considering as a quality measure in enhancing research utility. Furthermore, some of the elements in the framework are similar to those suggested in the work of Johnston et al. (2017).
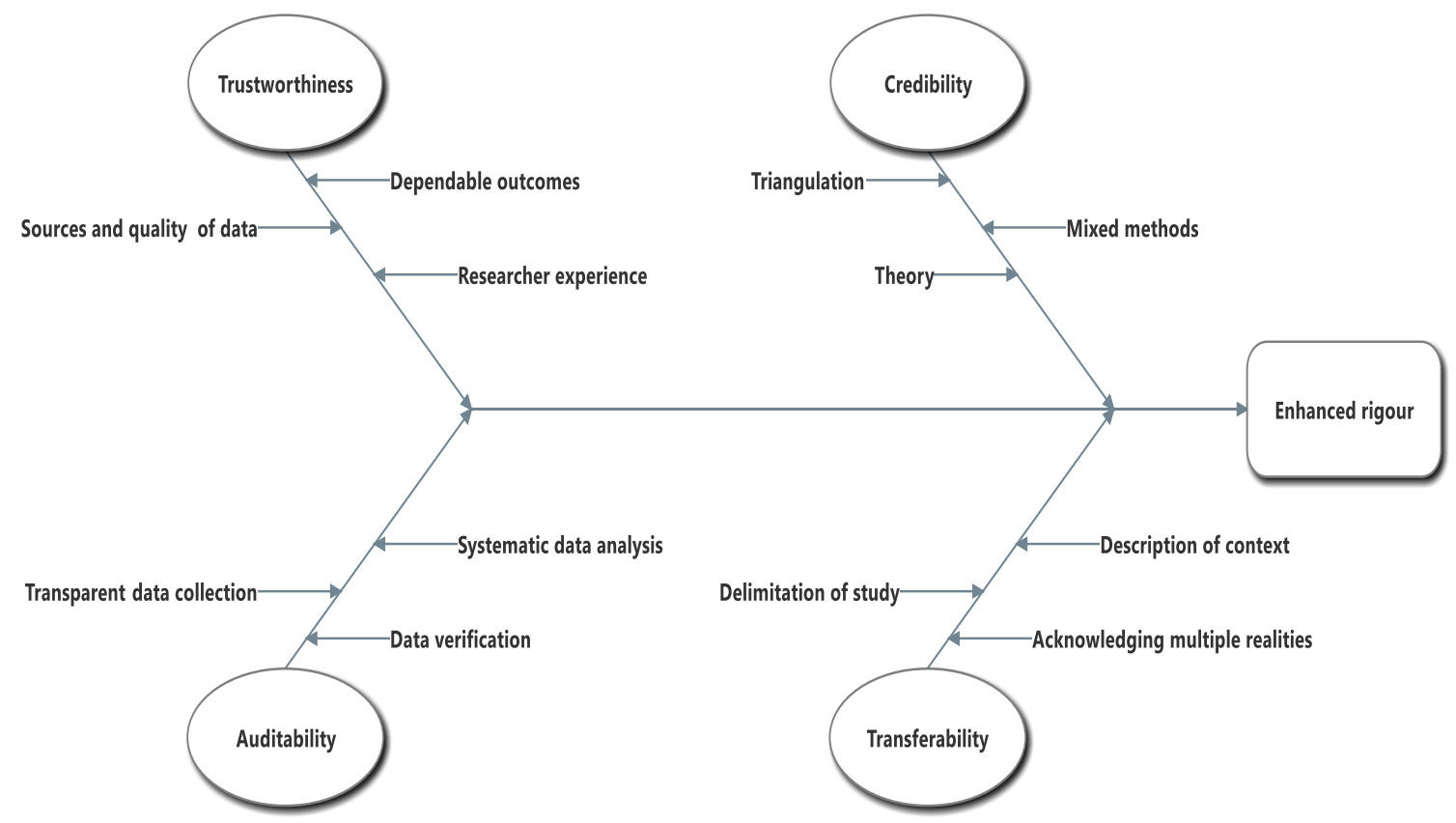

Figure 1: TACT model for assessing qualitative research outcomes

\subsection{Trustworthiness}

Trustworthiness is an essential concept in qualitative research methodology. The concept of 'trustworthiness' portrays quality in qualitative research and underpins both rigour in the research process and the relevance, and confidence in the research outcome (Baillie, 2015; Finlay 2006). Also, it is a proxy for establishing the authenticity of the research outcome, and truthfulness of findings (Cypress, 2017). Further, trustworthiness in qualitative research reveals the degree of trust or confidence; readers have in research findings (Carlson, 2010). On that basis, trust can be viewed as an element necessary for enhancing the understanding and interpretation of research findings.

Qualitative researchers are encouraged to demonstrate different ways in which the outcome of their studies can gain a certain level of trustworthiness. Subsequently, various models of trust have been developed in the past, but those models have not necessarily evolved with time and the discipline of qualitative research. For example, Guba's (1981) presented a model for establishing trust in qualitative research based on the identification of four aspects of trustworthiness: (a) truth value, (b) applicability, (c) consistency, and (d) neutrality. However, applying this model in qualitative research is not a straight forward process, time consuming and expensive. It requires the researcher to use different strategies and to ensure that findings are situated within views generated by participants (Lietz et al., 2006; Morrow, 2005; Sinkovics et al., 2008). Also, 
the researcher needs to acknowledge personal biases and to accept that the outcomes of any qualitative research are subject to multiple realities. For instance, the researcher establishes the trustworthiness of data analysis by explicitly stating their assumptions about the phenomenon being studied, and stating the experiences they bring to guide their understanding of the data through the tools of reflexivity (Meyrick, 2006).

Reflexivity requires the researcher to provide a detailed account of their experiences, assumptions about the phenomenon being explored, and the process and circumstances that inform the data collection process. Krefting (1991) added the notion of neutrality as an essential criterion for ensuring trustworthiness in a study.

Neutrality is a degree to which findings reflect participants' views outside of researchers' personal opinions. Further, trustworthiness is achieved when users of the qualitative research project can develop a better interpretation of the outcomes of a study and relate such outcomes to their experiences.

To achieve trustworthiness in qualitative research outcome, it is necessary to employ a systematic process in organising and analysing data (e.g. coding, identifying shared themes, categorising themes, and demonstrating a clear theoretical or logical rationale for eliminating overlapping themes) (Creswell \& Miller, 2000). In some cases, it is necessary to demonstrate consistency in coding and interpretation of data through intercoder or interrater reliability. It is worth noting that establishing trustworthiness in qualitative does not imply subscribing to one unified ontology, or embracing a universal epistemology, but rather demonstrating an acceptable degree of integrity in the process of carrying out the research and the outcome of the study. As Bailey (2007, p. 181) noted: "trustworthiness does not mean that the reader necessarily has to agree with the researcher; rather it requires the reader can see how the researcher arrived at a conclusion".

Achieving trustworthiness of a study in the context of the TACT framework requires the researcher to acknowledge their prior assumptions and experiences they bring to the study. Also, they need to demonstrate a systematic approach in the analysis of data and carry out verification of preliminary findings with participants to ensure that the outcome reflects views of the sample. Whenever possible, it is necessary to triangulate findings against other methods of inquiry.

\subsection{Auditability}

Auditability is a critical dimension for establishing rigour in qualitative research, and it requires the demonstration of transference in the research process. Auditability requires the application of a systematic procedure for collecting, analysing and interpretation of data. It also entails a detailed step-by-step description of the processes and decision-making throughout the study (Johnson, Adkins, and Chauvin, 2019). The literature suggests two types of auditability: external and internal auditability. External auditability is typically carried out by users of the research outcome. It is performed when the researcher's findings or conclusions are suspected and subjected to verification. Moreover, internal auditability relates to the ability of the researcher to address methodological issues including stating clarity in the research question, and how questions are aligned with particular research design, analysis of data, and conclusions drawn (Halpern, 1983).

Auditability is vital in qualitative research because it facilitates reflection on the researcher's part to ensure that the process of undertaking the research is fully documented and described. It is the provision of record keeping of all decisions made during the research process. Guba and Lincoln $(1989$, p. 243) termed this as an "audit trail". Typically, researchers interested in achieving an acceptable level of audibility utilise field notes, memos, and pictures, etc. during clear data collection, analysis-coding pathways and reporting.

To achieve auditability within the TACT framework, the researcher needs to describe how they engaged with the entire process of undertaking the research. It requires the researcher to illustrate the research evidence clearly and document their thought processes that led to the conclusions in a study. Such a process would, for example, require the researcher to describe who was involved in the study, how data was collected, where and when data was collected, and how the analysis was undertaken.

\subsection{Credibility}

The notion of credibility in qualitative research is similar to the concept of internal validity in quantitative research methods. Internal validity in the quantitative research tradition refers to an approximation of the truth of inference. In the context of qualitative research, validity is equitable to ensuring "appropriateness" of 
the tools, processes, and data used in the study. It also means that the researcher can show that the choice of the research design research is appropriate to the questions, the application of data collection methods, and analysis, and the reporting of the outcome (Cook, Kuper, Hatala \& Ginsburg, 2016; Leung, 2015). Similar to trustworthiness, achieving credibility will require showing how reflexivity and triangulation were achieved (Hammarberg, Kirkman \& de Lacey, 2016). Further, credibility can also require establishing that findings are dependable, relevant, and congruent - reflecting a researcher's intended reality that is obtained from the perspectives of those who provided data (Sandelowski, 1986; Patton, 2002). Noble and Smith (2015) pointed out that it is crucial for all qualitative researchers to incorporate strategies to enhance the credibility of a study during research design and implementation.

Similar to auditability, credibility is achieved through a careful description of the data analysis and verification of sources of data obtained with participants from whom data was collected. It also requires researchers to anchor the unit of data analysis in the central phenomenon being investigated (Daniel, 2018). Creswell (2009) suggested that "the final report or the description or themes" are taken back to the participants for verification purposes, a process referred to as member checking (Loh, 2013).

Peer debriefing, attention to negative cases, independent analysis of data by more than one researcher (interrater reliability), or the use of verbatim quote are other ways of establishing the degree of credibility in research findings. Further, credibility is achieved by the researcher describing his or her experiences as a researcher and verifying the research findings with the participants (Cope, 2014). Others suggested that credibility is obtained with a prolonged and varied engagement with the research setting (Forero, at al 2018).

Triangulation is considered a critical element of credibility in qualitative research methods. Triangulation relates to the convergence of data obtained using two or more data sources. It is used as a mechanism to substantiate findings by using one method and, corroborated the outcome with another, and also to gain a comprehensive view of the phenomenon (Cope, 2014). However, triangulation can be impossible to carry out due to the limitation in time or resources.

The credibility dimensions in the TACT framework entails the use of data verification, description of the researchers approach to the data analysis, engaging with participants during data analysis to verify the preliminary outcome of the analysis, and the use of direct quotations.

\subsection{Transferability}

Transferability in qualitative research suggests that findings from one study can be applied to other settings or groups of people (Houghton, Casey, Shaw, \& Murphy, 2013). It is congruent to the concept of reliability in a quantitative methodology (Lincoln and Guba, 1985; Golafshani, 2003). However, in contrast to the quantitative epistemology, transferability does not advocate for generalability (Lincoln et al. 2017; Smith \& McGannon 2017; Smith, 2018) but instead, it suggests that findings gained in a particular context can offer valuable lessons to other similar settings. Transferability is used to provide evidence to the reader to assess the integrity of research outcomes (Cope, 2014).

Transferability requires ensuring that the content of the interviews, the behaviours, and observed events are typical or atypical of the lives of the participants (Krefting, 1991). It also requires a detailed description of the context of the study, sample characteristics, participants (e.g. demographic information, their experiences (Hannes, 2011), and the methods used to recruit the sample and the types of data obtained. As Forero et al. (2018) reported that to demonstrate transferability, the researcher ensures that the recruitment and selection of a sample are based on expert knowledge of participants, and participants are knowledgeable about the phenomenon under study. Another means of ensuring transferability is to compare the characteristics of the participants or informants to the demographic information available on the group being studied. In other words, a qualitative study is considered transferable if the findings have meaning to individuals not involved in the study or the readers of the research can associate the findings with their own experiences (Cope, 2014).

Qualitative researchers use thick descriptions of real-life settings and understandings of participants' worldviews not only to achieve transferability but to help bridge the gap between practitioners and researchers (Ospina, Esteve, \& Lee, 2018). 
In addition to the various ways of achieving transferability, in the context of TACT, to attain transferability, it is crucial for the researchers to clearly articulate the delimitation of the research and the context in which it is undertaken, including the choices researchers made during the process of data collection and analysis, and possible challenges they might have faced during the research.

The four dimensions of rigour in the TACT framework are not necessary measures of rigour, but important indicators for researchers to think about how they can best increase the quality of research outcome, by addressing one or more of the dimensions. To use the TACT framework, a checklist of questions (Table 1) were developed against each one of the TACT's dimension. The questions are aligned with the most critical aspects of research methodology (research problem, methods, data analysis, and findings). Teachers of qualitative research methods can use this set of checklists as a pedagogic tool in a workshop setting; therefore, no scoring system is required at this stage until the more data collected on the dimensions, and the checklists are subjected to experts validation.

Table 1: Checklist of examples of questions on each of the TACT dimensions

Key: Trustworthiness (Tr); Auditability (Au); Credibility (Cre); Transferability (Trf)

\begin{tabular}{|c|c|c|c|c|}
\hline & Research Problem & Methods & Data analysis & Findings \\
\hline $\mathrm{Tr}$ & $\begin{array}{l}\text {-Is the research problem } \\
\text { framed within the context } \\
\text { of related literature? } \\
\text {-Does the researcher } \\
\text { clearly describe their } \\
\text { background? } \\
\text { - Does the researcher's } \\
\text { background have any } \\
\text { degree of familiarity with } \\
\text { the phenomenon and the } \\
\text { setting under the } \\
\text { proposed study? }\end{array}$ & $\begin{array}{l}\text {-Are the methods } \\
\text { used for data } \\
\text { collection appropriate } \\
\text { for the type of } \\
\text { research problem } \\
\text { proposed? } \\
\text { - Was the recruitment } \\
\text { strategy appropriate to } \\
\text { the aims of the } \\
\text { research? }\end{array}$ & $\begin{array}{l}\text { - Has the relationship between } \\
\text { the researcher and participants } \\
\text { been adequately considered? } \\
\text {-Can it be verified that data } \\
\text { presented reflect the views of } \\
\text { the participants? } \\
\text {-How was the data was } \\
\text { analysed (codes, themes, } \\
\text { theory, etc.)? } \\
\text {-Are the themes extracted from } \\
\text { data match examples of the } \\
\text { quotation? } \\
\text {-ls the analysis based on an } \\
\text { established and relevant } \\
\text { method? }\end{array}$ & $\begin{array}{l}\text {-Are the outcomes of the } \\
\text { research dependable? } \\
\text {-Is the conclusion drawn } \\
\text { from the data adequately } \\
\text { relate to the research } \\
\text { problem? } \\
\text {-Does the conclusion } \\
\text { recognise that multiple } \\
\text { realities exist? } \\
\text {-Has the researchers' } \\
\text { outlined personal } \\
\text { experiences and } \\
\text { viewpoints that may have } \\
\text { resulted in methodological } \\
\text { bias? } \\
\text {-Do the findings clearly ano } \\
\text { accurately presents the } \\
\text { participants' perspectives? }\end{array}$ \\
\hline $\mathrm{Au}$ & $\begin{array}{l}\text {-Is the research problem } \\
\text { clearly described? }\end{array}$ & $\begin{array}{l}\text {-Was the data } \\
\text { collection process } \\
\text { transparent? }\end{array}$ & $\begin{array}{l}\text {-Is the data analysis process } \\
\text { systematic? } \\
\text {-Are the decisions made } \\
\text { during data analysis fully } \\
\text { described? }\end{array}$ & $\begin{array}{l}\text {-Are the findings verified } \\
\text { against the stated research } \\
\text { problem? } \\
\text {-Does the researcher } \\
\text { clearly describe how data } \\
\text { was collected, where, } \\
\text { when, how and how the } \\
\text { analysis was undertaken? } \\
\text { - Can another researcher } \\
\text { follow the decision trail } \\
\text { used by the investigator in } \\
\text { the study? }\end{array}$ \\
\hline Cre & $\begin{array}{l}\text {-Is the research problem } \\
\text { adequately justified? }\end{array}$ & $\begin{array}{l}\text {-Can data be } \\
\text { triangulated? } \\
\text {-Are the methods } \\
\text { used for data } \\
\text { collection } \\
\text { appropriate? }\end{array}$ & $\begin{array}{l}\text {-Does the study lend itself to a } \\
\text { multidisciplinary approach, } \\
\text { likely to be investigated from a } \\
\text { number of different theoretical } \\
\text { perspectives? }\end{array}$ & $\begin{array}{l}\text {-Can finding be } \\
\text { theoretically verified? } \\
\text { - Can the accuracy of the } \\
\text { findings be established? } \\
\text { - Is there any congruence } \\
\text { between findings with } \\
\text { assumptions? } \\
\text {-Do the findings contribute } \\
\text { to any new knowledge? } \\
\text {-Can a degree of neutrality } \\
\text { in the research study's } \\
\text { findings be established? }\end{array}$ \\
\hline
\end{tabular}




\begin{tabular}{|lllll|}
\hline & Research Problem & Methods & Data analysis & Findings \\
\hline Trf & $\begin{array}{l}\text {-Is the research problem } \\
\text { clearly described? }\end{array}$ & $\begin{array}{l}\text {-Are the methods of } \\
\text { data collection clearly } \\
\text { described? }\end{array}$ & $\begin{array}{l}\text {-Is the approach for data } \\
\text { collection clearly described? }\end{array}$ & $\begin{array}{l}\text {-Are multiple realities } \\
\text { acknowledged? }\end{array}$ \\
& $\begin{array}{l}\text {-Are participants' } \\
\text {-ls there a detailed } \\
\text { description of the study } \\
\begin{array}{l}\text { context, times and } \\
\text { phenomenon }\end{array}\end{array}$ & $\begin{array}{l}\text { characteristics clearly } \\
\text { described? }\end{array}$ & & $\begin{array}{l}\text {-Is the currency of findings } \\
\text { and applicability } \\
\text { transferable to similar } \\
\text { context? }\end{array}$ \\
\hline
\end{tabular}

\section{Context and Pedagogical Intervention}

The TACT project is part of a research-led pedagogical initiative aimed at improving the way we approach the design and delivery of analytics and research methods (ARM) in higher education. ARM is a series of workshops on research methodologies, analytical data models and digital technologies, offered by Higher Education Development Centre (HEDC) at the University of Otago, New Zealand. The goal of the series is to provide research literacy and comprises of introductory as well as advanced training in research methodologies and analytical frameworks for postgraduate students and staff in the Social Sciences, Humanities, Health, and the Sciences.

To test the TACT framework, a professional development workshop was developed to teach postgraduate students about issues of rigour. The workshop was offered ten times, attracting a total of 64 participants (postgraduate students and academic staff) at the University of Otago, New Zealand. Participants explored the various dimensions of the framework and reflected upon their own projects. The workshop begins with an introduction to qualitative research methodology, covering theoretical and philosophical underpinning of qualitative research, framing research questions and design, developing a systematic approach to the analysis of qualitative data, and various ways of reporting findings. Participants were then introduced to the notion of rigour, and the principles and dimensions of the TACT framework. Each workshop lasted for three hours, which is the standard time allocated to delivering professional development workshops at our university.

To determine the pedagogical value of TACT, and its contribution to learning issues of rigour in qualitative research, the workshops were evaluated, using five standard questions used in student evaluation at the university (see questions in table 2).

Table 2: Standard evaluation questions

\begin{tabular}{ll}
\hline Questions & Rating/response \\
\hline How valuable do you think this workshop has been for & Extremely valuable 12345 Not valuable at all \\
you? & \\
Overall, how effective have you found the facilitation of & Extremely valuable 12345 Not valuable at all \\
this workshop? & \\
What were the best things about this workshop for you? & \\
How could this workshop be improved? & \\
What topics would you like addressed in future? & -
\end{tabular}

\section{Evaluation and student experience}

Generally, participants reported that the workshops were valuable and enjoyable (see table 3 and 4), stating that participating in the workshops provided them with a better understanding of the theoretical and practical issues around qualitative research methodology:

"This workshop has given me a much clearer idea of issues in qualitative research. Concepts were explained clearly, and important issues discussed. It will certainly inform my research."

"Having someone speak about methodology and explain things makes methodology much clearer and puts things into perspective. Meeting up with other students and hearing their situations and queries." 
Those participants who were studying for PhD and using qualitative research methodology in their research mainly found the workshops useful, refreshing, and reassuring, and participating in the workshops provided some participants with the necessary confidence in conducting qualitative research:

"Excellent presenter, very warm, friend and engaging, who explained things very clearly with examples. This presentation was a big help for me being 2/3 through a PhD."

"Refreshing my knowledge it has been a while since I completed my Masters. Hopefully, I will have a little more confidence to move forward with some nursing research."

"Reassurance that I am doing the right thing. Overview of different methodologies. Introduction to TACT framework."

Table 3: Participants and workshops ratings

\begin{tabular}{lccc} 
Workshop & $\begin{array}{c}\text { Total number of } \\
\text { participants }(\mathbf{n = 6 4 )}\end{array}$ & $\begin{array}{c}\text { The overall value of the workshop } \\
\text { to participants (\%) }\end{array}$ & $\begin{array}{c}\text { The overall quality of teaching } \\
\text { rating (\%) }\end{array}$ \\
\hline Workshop 1 & 14 & 79 & 86 \\
Workshop 2 & 11 & 82 & 45 \\
Workshop 3 & 6 & 100 & 83 \\
Workshop 4 & 5 & 100 & 100 \\
Workshop 5 & 6 & 100 & 100 \\
Workshop 6 & 6 & 100 & 100 \\
Workshop 7 & 7 & 100 & 100 \\
Workshop 8 & 2 & 100 & 100 \\
Workshop 9 & 3 & 67 & 67 \\
Workshop 10 & 9 & 89 & 89 \\
\hline
\end{tabular}

Table 4: Average ratings of the value and teaching effectiveness on each workshop

\begin{tabular}{lcc}
\hline Workshops (W) & $\begin{array}{c}\text { How valuable do you think this } \\
\text { workshop has been for you? (average } \\
\text { rating) }\end{array}$ & $\begin{array}{c}\text { Overall, how effective have you found the } \\
\text { facilitation of this workshop? (Median rating) }\end{array}$ \\
W1 & 1.8 & 1.8 \\
W2 & 1.9 & 2.9 \\
W3 & 1.3 & 1.5 \\
W4 & 2 & 1.3 \\
W5 & 1.8 & 1.9 \\
W6 & 1.8 & 1.8 \\
W7 & 1.1 & 1.4 \\
W8 & 2 & 2 \\
W9 & 2 & 2 \\
W10 & 1.6 & 1.8 \\
Overall median & $\mathbf{1 . 7}$ & $\mathbf{1 . 8}$ \\
\hline
\end{tabular}

Also, participants indicated that the materials covered in the TACT framework were adequate and informative:

"I thought the material was covered well, I have never been to a structured talk on this topic, and it was very reassuring to know what I would previously read and applied (to manuscript write up) was not too far off what a domain expert was saying. This was reassuring..."

"...I found the slides, in particular, the tables and diagrams outlining the types of qualitative methods, the process of coding and then generating themes from qualitative data very clear and useful."

In addition to the high rating of the value of the workshop (92\%), participants also felt that the facilitation of the workshops was effective (87\%). 
"The facilitator was very comfortable with being asked questions and was very nimble with his answers. I think his pre-workshop questionnaire about participants' methodologies and attitudes allowed him to respond to an individual participant in a way that kept the issue very relevant to her actual research. He was, for instance, able to provide concrete advice relevant to the individual's particular problem as opposed to more abstract and generalised advice that would not have been as helpful."

"The facilitator is the best presenter/teacher I have had in all my courses with the University this year. He is knowledgeable and does not make you feel ashamed to ask a question that sounds "silly". He is extremely good at getting a complex issue understood by breaking it up into understandable bits."

Further, participants described the presentation of the TACT framework as well structured, engaging and clear: "the whole structure and outline and areas covered were great. The facilitator was an amazing teacher and presented everything in a very clear and logical way. It was great how he took examples and used these to highlight aspects of qualitative research." "The facilitator was very engaging, knowledgeable and answered questions well."

".... also found the discussion with the attendees really good. People were at different stages in their qualitative research, so it was good to hear how they related to what the facilitator was saying from their own experiences."

Others found the nature of engagement and interactions in workshop useful; "I appreciated the knowledge and the interactivity with the facilitator and the other participants in the workshop." and others appreciated the opportunity to ask questions during the workshops: "I found the workshop interactive. I could ask questions which were specific to me, and the lecturer took time and answered them well." The interactive mode of workshop facilitation was considered appropriate, since, workshop participants are diverse, and have different interests, it is critical to forming group activities that allow participants to share their experiences with others, and adapt the materials to their own experiences.

In addition to the participants' description of their experiences in the workshops, a Word cloud with a visual summary of words that appear more frequently in the text is provided in figure xxx. Participants described their experiences in the workshop as "extremely interactive", "engaging"; "personalised and well structured"; "applied", "responsive", etc. 


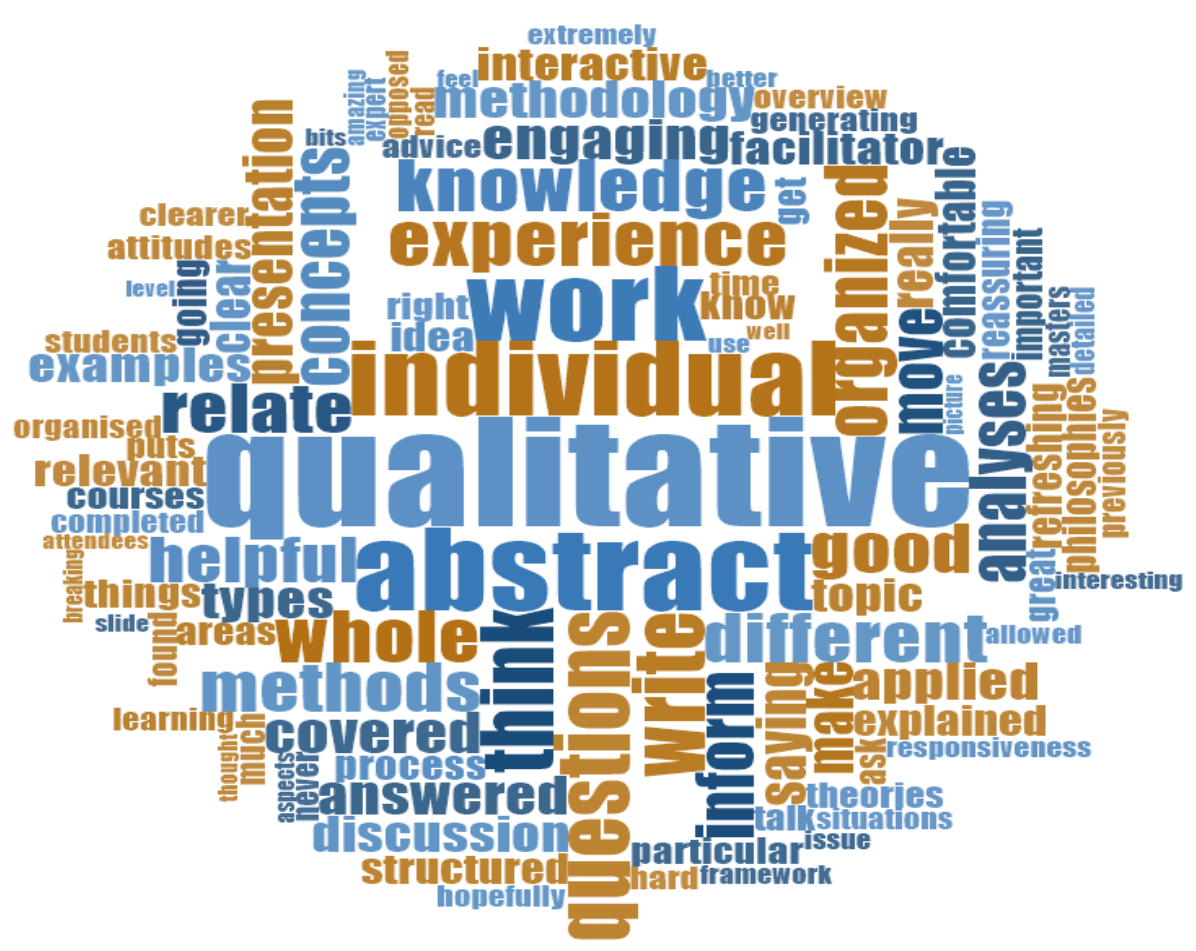

Figure 2: A word cloud of the text describing workshop participants' experience

\subsection{Suggested pedagogical enhancement}

Although the workshops evaluated well, participants suggested some ways to improve the workshops. They indicated that they would have liked to see more examples that relate to their domains in the discussions. For instances, one participant said; "a few more examples, if it were a more extended workshop, might be useful. For those that are new to the idea I realised that it would have been good for me to have read a few good examples of published qualitative work beforehand, but I know that many will already be familiar with it."

Some participants suggested more time dedicated to the application of the framework. "I think it needs more time to discuss coding and TACT model in more details with more example, especially in the case of TACT." "Some time for reflection or application of the material to our research, something similar to the "6-minute writing" exercise in the thesis writing workshop would be fantastic, to cement the material for us....."

"The workshop could almost be an all-day workshop incorporating breakout sessions where participants have peer to peer discussions relating to their methodologies and then report back to the group. Such activities might help to embed the learning."

Overall, the results of the evaluation of the workshop suggest that the TACT framework is useful in teaching students issues of rigour in qualitative research. Participants also reported an enhanced learning experience in qualitative research methodology. However, the pedagogical design of the TACT workshops requires improvement, especially in their design. More examples in how the TACT could be used and more time for participants to explore, discuss and use the TACT framework in their projects will be required in future workshops.

\section{Summary and future research directions}

The qualitative research methodology is considered a legitimate approach to the exploration of complex phenomena across disciplines and domains. Despite its growing contribution to methodological scholarship, the value of qualitative research methodology has come under constant criticism. Critiques describe qualitative research as anecdotal, bias, and limited in its generalisability power (Cope, 2014; Hayashi, Abib \& Hoppen, 2019). The lack of validity and replicability of qualitative research findings is attributed to the inconsistent application of methods and a lack of a universal set of criteria to judge the qualitative of research findings (Barbour, 2001; Daniel, 2018; Filep, at al 2018). 
Researchers engaged in qualitative research rarely provide an adequate justification for the methods they use(Noble \& Smith, 2015). For instance, Saunders and Townsend (2016) examined 798 articles published between 2003 and 2013 in ten top and second-tier academic journals in the area of organisation and workplace research and identified a lack of transparency in reporting participants selected for studies and justification for sampling choices in half of the studies. Similarly, Ospina et al. (2018) conducted a systematic review of 129 qualitative research methods in the public administration, published during five years (2010-14), and confirmed the inconsistency in reporting methodological decisions. The lack of consistency in the use of qualitative research methods threatens the credibility of the methodology. It is, therefore, vital that the quality of research needs to be checked against the soundness of the problem formulation, research design, theoretical depth, methods for data collection, and the conclusion drawn.

The notion of rigour in qualitative research needs to be brought back to theoretical and pedagogical discussions. Rigour is necessary to achieve because it ensures the integrity of the research and increases the authenticity of research outcomes. Also, gaining rigour in qualitative research puts a degree of accountability on the researchers during the research process and implications of the outcomes. Moreover, providing standardised indicators for assessing quality, enables users of qualitative research outcomes to systematically inspect, and verify, the relevance of particular research findings.

This article presented the TACT framework as a useful proxy for exploring dimensions of rigour in qualitative research. TACT appeals for the establishment of a standard set of indicators that can be used to explain, and achieve issues of rigour to students and those new to qualitative research. Also, the TACT framework can be utilised as a tool to guide academic peer-review of qualitative research studies, as well as a pedagogical framework for teachers of qualitative research methods. In order to implement the TACT framework, various strategies can be employed by the researcher guided by the checklist provided in table 1 . For instance, to ensure the trustworthiness of a study, the researcher applies a systematic approach to data analysis and reporting.

Similarly, being systematic and transparent during data analysis and other aspects of the research can provide others with the ability to audit trail the research findings. Moreover, the ability to verify the findings of a research study enables consumers of research findings to establish the credibility of the research outcome.

Further, since qualitative research does not often include generalised findings from a sample to the population from which the sample is withdrawn, the researcher can provide a detail description of the context of the research, background information about participants to allow for transferability of findings from one context to similar contexts or groups. Transferability provides readers with rich, and vivid quotes from the participants to substantiate the interpretations of outcome (Cope, 2014).

Though the framework has been used in several workshops. Those who participated in the workshops by large reported that the workshops provided them with a better understanding of qualitative research methodology in general, and issues of rigour. The TACT framework seems to be an effective tool for learning issues of rigour.

However, participants suggested an improvement in the way workshops were designed and delivered. Two versions of the workshop on TACT framework are being developed with one focusing on an introduction to TACT and an advanced one aimed at teaching students how to apply the TACT framework to achieve rigour in their research projects. Concurrently, there is an ongoing verification of its efficacy for learning rigour. It is possible that TACT might not be widely applicable to all qualitative research problems since the concept of rigour is contested in the qualitative research methods literature.

The TACT framework presented in this article provides a critical and systematic approach to teaching, and addressing issues of rigour qualitative methodology. It is vital to engage in the dialogue on rigour in qualitative research since the credibility and dependability of qualitative research outcomes are often questioned. Also, researchers tend to approach qualitative research differently, therefore, maintaining consistency in the use methods and interpretation is essential in achieving rigour. However, it is also likely that qualitative researchers might contest the use of the TACT framework because such a framework closely appeals to the positivist epistemology of measurability in the scientific methods. Nonetheless, the framework itself is essential as pedagogical and platform for dialogue on issues of quality in qualitative research findings. In the 
future, it is essential to validate the checklists, a group of experts will be invited to examine and refine the checklist and use the outcome to guide students in learning the fundamental indicators of rigour.

\section{Acknowledgements}

The author would like to thank students and academic staff who participated in the TACT workshops and providing useful feedback.

\section{Funding}

This work was supported by the Internationalisation of Curriculum Grant awarded by the University of Otago, New Zealand.

\section{Reference}

Baillie, L. (2015). Promoting and evaluating scientific rigour in qualitative research. Nursing Standard, 29(46), 36.

Bailey, C. A. (2007). A guide to qualitative field research (2nd Ed.). Thousand Oaks, CA: Pine Forge Press.

Barbour, R. S. (2001). Checklists for improving rigour in qualitative research: a case of the tail wagging the dog? BMJ, 322(7294), 1115-1117.

Camfield, L. (2019). Rigour and ethics in the world of big-team qualitative data: Experiences from research in international development. American Behavioral Scientist, 63(5), 604-621.

Carlson, E. A. (2010). Evidence-Based Practice for Nurses: Appraisal and Application of Research. Orthopaedic Nursing, 29(4), 283.

Cook, D. A., Kuper, A., Hatala, R., \& Ginsburg, S. (2016). When assessment data are words: validity evidence for qualitative educational assessments. Academic Medicine, 91(10), 1359-1369.

Creswell, J. W. (2009). Designing a qualitative study: Qualitative, quantitative and mixed. Methods approach (3rd Ed). Thousand Oaks, CA: Sage Publications.

Cope, D. G. (2014, January). Methods and Meanings: Credibility and Trustworthiness of Qualitative Research. In Oncology Nursing Forum, 40(1), 89-91).

Creswell, J. W., \& Miller, D. L. (2000). Determining validity in qualitative inquiry. Theory into Practice, 39(3), 124-130.

Cypress, B. S. (2017). Rigour or reliability and validity in qualitative research: Perspectives, strategies, reconceptualisation, and recommendations. Dimensions of Critical Care Nursing, 36(4), 253-263.

Daniel, B. K. (2018). Empirical verification of the "TACT" framework for teaching rigour in qualitative research methodology. Qualitative Research Journal, 18(3), 262-275.

Dixon-Woods, M., Shaw, R. L., Agarwal, S., \& Smith, J. A. (2004). The problem of appraising qualitative research. BMJ Quality \& Safety, 13(3), 223-225.

El Hussein, M., Jakubec, S. L., \& Osuji, J. (2015). Assessing the FACTS: A mnemonic for teaching and learning the rapid assessment of rigour in qualitative research studies. The Qualitative Report, 20(8), 0_1.

Forero, R., Nahidi, S., De Costa, J., Mohsin, M., Fitzgerald, G., Gibson, N., \& Aboagye-Sarfo, P. (2018). Application of fourdimension criteria to assess the rigour of qualitative research in emergency medicine. BMC health services research, 18(1), 120.

Filep, C. V., Turner, S., Eidse, N., Thompson-Fawcett, M., \& Fitzsimons, S. (2018). Advancing rigour in solicited diary research. Qualitative Research, 18(4), 451-470.

Finlay, L. (2006). 'Rigour', 'ethical integrity 'or 'artistry'? Reflexively reviewing criteria for evaluating qualitative research. British Journal of Occupational Therapy, 69(7), 319-326.

Golafshani, N. (2003). Understanding reliability and validity in qualitative research. The qualitative report, 8(4), 597-606.

Guba, E. G. (1981). Criteria for assessing the trustworthiness of naturalistic inquiries, Educational Communication and Technology Journal, 29 (2), 75-91.

Guba, E. G., \& Lincoln, Y. S. (1981). Effective evaluation: Improving the usefulness of evaluation results through responsive and naturalistic approaches. San Francisco, CA: Jossey-Bass.

Halpern, ES. (1983). Auditing Naturalistic Inquiries: The Development and Application of a Model. Unpublished Doctoral Dissertation, Indiana University.

Hammarberg, K., Kirkman, M., \& de Lacey, S. (2016). Qualitative research methods: when to use them and how to judge them. Human Reproduction, 31(3), 498-501.

Hannes K. (2011): Critical appraisal of qualitative research. In: Noyes J, Booth A, Hannes K, Harden A, Harris J, Lewin S, Lockwood C (editors), Supplementary Guidance for Inclusion of Qualitative Research in Cochrane Systematic Reviews of Interventions. Version 1 (updated August 2011). Cochrane Collaboration Qualitative Methods Group, 2011. Available from URL http://cqrmg.cochrane.org/supplemental-handbook-guidance.

Hartman, T. (2015). 'Strong multiplicity': an interpretive lens in the analysis of qualitative interview narratives. Qualitative Research, 15(1), 22-38.

Houghton, C., Casey, D., Shaw, D., \& Murphy, K. (2013). Rigour in qualitative case-study research. Nurse Researcher, 20(4), 12-17.

Hayashi, Jr, P., Abib, G., \& Hoppen, N. (2019). Validity in Qualitative Research: A Processual Approach. The Qualitative Report, 24(1), 98-112. 
Johnston, C. M., Wallis, M., Oprescu, F. I., \& Gray, M. (2017). Methodological considerations related to nurse researchers using their own experience of a phenomenon within phenomenology. Journal of advanced nursing, 73(3), 574-584.

Johnson, J. L., Adkins, D., \& Chauvin, S. (2019). Quality Indicators of Rigor in Qualitative Research. American Journal of Pharmaceutical Education, ajpe7120.

Koch, T. (2006). Establishing rigour in Qualitative Research: the decision trail. Journal of Advanced Nursing. 53, (1), 91-103.

Koch, L. C., Niesz, T., \& McCarthy, H. (2014). Understanding and reporting qualitative research: An analytical review and recommendations for submitting authors. Rehabilitation Counseling Bulletin, 57(3), 131-143.

Krefting, L. (1991). Rigour in qualitative research: The assessment of trustworthiness. American journal of occupational therapy, 45(3), 214-222.

Leung, L. (2015). Validity, reliability, and generalizability in qualitative research. Journal of family medicine and primary care, 4(3), 324.

Lietz, C. A., Langer, C. L., \& Furman, R. (2006). Establishing trustworthiness in qualitative research in social work implications from a study regarding spirituality. Qualitative Social Work, 5(4), 441-458.

Loh, J. (2013). Inquiry into issues of trustworthiness and quality in narrative studies: A perspective. The qualitative report, 18(33), 1-15.

Morrow, S. L. (2005). Quality and trustworthiness in qualitative research in counselling psychology. Journal of counselling psychology, 52(2), 250.

Morse, J. M., Barrett, M., Mayan, M., Olson, K., \& Spiers, J. (2002). Verification strategies for establishing reliability and validity in qualitative research. International journal of qualitative methods, 1(2), 13-22.

Morse, J. M. (2015). Critical analysis of strategies for determining rigour in qualitative inquiry. Qualitative health research, 25(9), 1212-1222.

Meyrick, J. (2006). What is good qualitative research? The first step towards a comprehensive approach to judging rigour/quality. Journal of health psychology, 11(5), 799-808.

Noble, H., \& Smith, J. (2015). Issues of validity and reliability in qualitative research. Evidence-based nursing, 18(2), 34-35.

Ospina, S. M., Esteve, M., \& Lee, S. (2018). Assessing qualitative studies in public administration research. Public Administration Review, 78(4), 593-605.

Patton, M.Q. (2002). Qualitative Research and Evaluation Methods. Thousand Oaks, CA: Sage.

Sandelowski, M. (1986). The problem of rigour in qualitative research. Advances in nursing science, 8(3), 27-37.

Saunders, M. N., \& Townsend, K. (2016). Reporting and justifying the number of interview participants in organ isation and workplace research. British Journal of Management, 27(4), 836-852.

Shenton, A. K. (2004). Strategies for ensuring trustworthiness in qualitative research projects. Education for information, 22(2), 63-75.

Sinkovics, R. R., \& Ghauri, P. N. (2008). Enhancing the trustworthiness of qualitative research in international business. Management International Review, 48(6), 689-714.

Smith, B. (2018). Generalizability in qualitative research: misunderstandings, opportunities and recommendations for the sport and exercise sciences, Qualitative Research in Sport, Exercise and Health, 10:1, 137-149, DOI: 10.1080/2159676X.2017.1393221

Smith, B. and McGannon K.R., (2017). Developing rigour in qualitative research: problems and opportunities within sport and exercise psychology. International review of sport and exercise psychology. Advance online publication. DOI:10.1080/1750984X.2017.1317357.

Tong, A., \& Dew, M. A. (2016). Qualitative research in transplantation: Ensuring relevance and rigour. Transplantation, 100(4), 710-712.

Yardley, L. (2000). Dilemmas in qualitative health research. Psychology and health, 15(2), 215-228. 